\title{
Online Instructional Materials for Students with Disabilities: Does it Work?
}

\author{
Jeanine L. Wilson ${ }^{1 *}$, Sally Berkowitz ${ }^{1}$, Corina Bullock ${ }^{1}$, Candace Cockrell ${ }^{1}$, \\ Lisa M. Rodriguez ${ }^{1}, \&$ Anthony J. Onwuegbuzie ${ }^{1}$
}

1 Sam Houston State University, Huntsville, TX, USA. E-mail: Sally Berkowitz (sgb013@shsu.edu), Corina Bullock (ckbullock@att.net), Candace Cockrell (ccockrel@houstonisd.org), Lisa M. Rodriguez (lrodrig5@houstonisd.org), and Anthony J. Onwuegbuzie (tonyonwuegbuzie@aol.com)

*Corresponding author: Jeanine L. Wilson, E-mail: jlw079@ shsu.edu

Received: June 14, 2012 Accepted: July 22, 2012 Published: August 1, 2012

doi:10.5296/ije.v4i3.1866 URL: http://dx.doi.org/10.5296/ije.v4i3.1866 


\begin{abstract}
In the context of online instructional programs, numerous topics have been addressed. The purpose of this study was to explore the implementation of the Renzulli Learning System (RLS) in a large public school district in the southwest area of the United States as a measure of using online instructional materials toward increasing academic achievement for students with special needs. Specifically, the study explored the implementation of the RLS in support of students who have been identified as learning disabled. Moreover, the study comprised 2,750 students in Grades 6 through 8 and examined simultaneously high and low utilization of RLS with respect to state assessment reading and mathematics scaled scores through the use of a multivariate analysis of variance. Findings revealed that when the utilization of RLS was high by students with learning disabilities, the reading scaled scores $(n=1,212)$ tended to be higher, whereas the mathematics scaled scores $(n=1,269)$ tended to be lower. Implications of the findings are presented and recommendations for future research are provided.
\end{abstract}

Keywords: online instructional programs, special education, motivation 
The use of online instructional tools has been explored in a variety of contexts around the world (Anderson \& Balajthy, 2009; Papa, 2010). Researchers have noted that, when used appropriately, computers, educational software, and web resources can contribute in a variety of ways toward creating effective learning environments (Herrington \& Oliver, 1999; Martindale, Cates, \& Qian, 2003; Snider, 1992). Moreover, online instruction has been a particular area of interest among individuals and organizations responsible for the development and implementation of innovative educational reform initiatives that call for new ways of learning and teaching (Bonner, 2011). In fact, many countries across Europe and North America have adopted information and communication technology (ICT) as a central component in school improvement and effectiveness planning where these technologies are seen as a complement rather than as a replacement to traditional teaching and learning approaches within schools (Condie \& Livingston, 2007). This interest is, in part, due to the available research in support of the positive effect that online learning programs have on learning outcomes (Simonson, Smaldino, Albright, \& Zvacek, 2003).

Educational leaders continue to face a growing frustration with stagnant levels of low student achievement as students fall further behind regardless of the efforts by educators to meet the diverse needs of the students. Equally, educational leaders are frustrated with stagnant levels of pedagogical practices because they believe that the instructional methods of the 19th century have been prohibitive to accelerating and challenging 21 st century students (Roschelle, Pea, Hoadley, Gordin, \& Means, 2000). The need academically to support all students is acknowledged; however, the need to support students academically who are behind and who never have an opportunity to master materials needed to progress is of paramount concern. To address this concern, online learning has increased in demand as school administrators across the country seek to level the playing field for all students by providing access to high quality, 21 st century instructional methods driven by the necessity to meet individual student needs.

Katie Ash (2011) documented that the number of technology-based online intervention companies, whose aim is to identify student learning challenges early and provide interventions to address those problems, has risen in the past year. In addition to the rise of companies whose purpose is to provide online instructional materials as a means of academic intervention, researchers have noted the need for growth in several categories, including school improvement, special education, and early childhood education (Ash, 2011). Koszalka and Ganesan (2004) indicated that many classrooms have been restructured to facilitate an online learning environment; yet, the process often fails when efforts are in accordance with a linear-designed instructional framework. As with all instructional strategies, when teachers are asked to implement an online learning environment using a prescribed format with minimal differentiation, the outcome will not be favorable for all students (Simonson et al., 2003).

There has been tremendous growth in the area of instructional technology as it relates to supporting the academic needs of general education students. Indeed, online instructional programs have been shown to increase active student engagement in the learning environment when implemented appropriately (Watson \& Ryan, 2007). In a recent study, Condie and Livingston (2007) provided evidence that students who utilized online instructional programs 
were encouraged to go beyond passive learning and to become more engaged in and responsible for their own learning. Roschelle et al. (2000) maintained that an "effective, broad-scale adoption of particular technologies is dependent on progress in adopting more challenging national and statewide goals by community stakeholders including teachers, parents, school boards, and administrators" (p. 91). Additionally, considerable research supports the hypothesis that online learning environments have a positive effect on learning outcomes (Simonson et al., 2003); can support higher-order learning (Paolucci, 1998), especially in mathematics (Nicaise, 1997); and can teach problem-solving skills to those who struggle with learning difficulties (Babbitt \& Miller, 1996).

Although most programs appear to offer high-quality educational options for students, inadequate pedagogical practices might threaten the sustainability of online learning for all students. Watson and Ryan (2007) attest to the need for reviewing the processes and outcomes of online instructional programs especially in the areas of student achievement outcomes; teacher training, supervision, and evaluation; and special education services. Moreover, Brown (2004) reported that shifting to an online instructional environment requires a thoughtful consideration of the most effective method for implementing such a program that optimizes instructor-learner interaction. A study in Florida revealed that general education fourth- and fifth-grade students who were examined solely on usage or non-usage of an online instructional program had significantly higher reading scores and mathematics scores than did non-users (Martindale, Pearson, Curda, \& Pilcher, 2005).

Improving academic achievement remains a seminal topic throughout the United States; as such, educational leaders continue to struggle with identifying effective online instructional tools for supporting students with learning disabilities (Papa, 2010). Professional development models have called for teachers to consider student needs and to differentiate instruction when using print materials as well as utilizing opportunities to incorporate online instructional resources in a variety of ways; however, the literature review conducted by the authors of this study has illuminated a gap in the availability and effective use of online instructional resources in support of special education students who have been mainstreamed. The finding of Anderson and Balajthy (2009) that teachers have a tendency to utilize technology tools without first examining them for appropriateness for individual student's needs, emphasizes a lack of consideration for supporting the varied levels of students identified with special needs.

Roschelle et al. (2000) raised the need for curriculum modernization and noted the increasingly rigorous curricular goals for science and mathematics where an emphasis has been placed on the use of instructional technology tools and resources to support student learning. As other content areas move toward the example set by science and mathematics experts, minimal exploration has occurred to support the varied needs of students with disabilities (Edyburn, 2003). However, Engel reported that iPads were introduced especially for students with learning disabilities into an Illinois school district. The dawn of Apple's popular multimedia device invoked a plethora of ideas for increasing productivity within every industry and has drawn the attention of educators on how to utilize the most effective instructional technology methods that the iPad affords. This phenomenon presents the integration of a technology device that appears to give students more individual access to 
curricular lessons as well as hands-on support that could be beneficial for students with special needs. In Engel's article, Maureen Langholf, the special education director for the Peoria, IL school district, purported that "a child with autism can use pictures and voice recordings and the touch technology to communicate" (Engel, 2011, p. 1). However, the development of equitable technology programs designed to provide individualized support to students with special needs remains a necessity.

Another example of the integration of a technology device to support the varied needs of students with disabilities occurred in a South Carolina private school where Amazon.com, Inc., the U.S. multinational electronic commerce company, donated Kindles, electronic readers with built-in wireless Internet capability, to serve special education students in Grades K through 12 (King, 2011). As the program blossomed, teachers anticipated using the Kindle as a means of enhancing classroom instruction for their students. Immediately upon implementation, students cited the device's ability to "enlarge font, read books aloud, and to keep multiple books in one place as a benefit" (King, 2011, p. 1). In this instance, the integration of a Kindle in support of academic progress for students with special needs speaks to the implementation of a technology device as opposed to the implementation of a technology program specifically designed to support students with special needs. The focus of this study is to examine the current need for technology programs designed for students with special needs. Data such as those revealed in the research of King (2011) and Engel (2011) demonstrate the implications for implementing technology devices into the learning environment; however, research related to the existence of effective technology programs is minimal.

As students utilize available online instructional activities to enhance understanding of key concepts while cultivating new questions instead of relying on a transfer of knowledge from their teachers, learning is transformed. This experience has been referred to as transformative learning (Mezirow, 1991). Certainly, online learning programs have the propensity to encourage transformative learning given the presence of meaningful dialogue based upon collaborative opportunities, authentic experiences, reflective participation, and interpretation of the instructional program experiences (Doering, 2005; Mezirow, 1991). Ultimately, the goal is to enable learners to understand why they see the world as they do while understanding the impact of prior knowledge on their newly constructed knowledge (Palloff \& Pratt, 1999).

The Sloan Consortium (2008) issued a report on the extent and nature of online learning in K-12 schools, highlighting the survey findings of school district administrators across the United States. Various departments within the school district where the study took place have utilized online instructional tools to support student learning; however, specific research dedicated to identifying online instructional programs that affect student achievement among students with disabilities is needed. In addition to the identification of online instructional programs, practical examples of successful implementation of the aforementioned programs are lacking.

Principles of teaching are well established in traditional methods of instruction (e.g., identifying similarities and differences, summarizing and note taking, cooperative learning). 


\section{Mll Macrothink}

International Journal of Education

ISSN 1948-5476

2012, Vol. 4, No. 3

These principles may generalize to learning in a transformative environment where online instructional programs are integrated. To facilitate a transformative learning environment rich in technology, researchers suggest the following components as being paramount to implementing an effective online instructional program: (a) use a learner-centered approach to optimize instructor-learner interaction, (b) provide ample opportunities to practice, (c) check learning progress and provide timely feedback and encouragement, (d) develop reciprocity and cooperation among students, and (e) communicate high expectations (Brown, 2004; Chickering \& Ehrmann, 1996; Jonasen, Strobel, \& Gottdenker, 2005; Lim \& Kim, 2003). Given these principles, limited research exists systematically to assess the application of the aforementioned principles to online instruction. Electronic delivery is merely one feature that clearly differentiates an online learning environment from other forms of instruction; however, too often, an online instructional program primarily is viewed as an instructional delivery system when the implementation of the online program is the impetus for successful pedagogy. Undeniably, pedagogy and implementation are most significant in online learning environments (Meyen et al., 2002).

To this end, it is imperative that school districts consider not only the benefits of online learning environments but also seek to identify ways in which an expansion of the outcomes associated with online learning moves beyond students in general education classes to students with learning disabilities. As strategies for teaching students with special needs are perfected and become best practices, so will the development of online learning programs. Condie and Livingston (2007) surmised that online learning programs have the propensity to provide opportunities that encourage students to go beyond passive learning and become more engaged in the learning process. As the aforementioned strategies are perfected, the ability to complement these strategies with the implementation of online instructional programs might capitulate beneficial results for students with special needs, namely, increased academic achievement.

\section{Renzulli Learning System}

In 2009, the school district discussed in this study implemented the Renzulli Learning System (RLS), an online instructional program, for all students in Grades K through 12. A subsequent program evaluation was conducted by the district's Research and Accountability Department to assess the implementation of the RLS and its impact on the academic achievement of these students. Due to the sparse research focusing on students with special needs in an online learning environment, this study was conducted in the school district where the evaluation ook place to examine further data related to the implementation of RLS. However, the emphasis of this study was solely on mathematics and reading instruction for special education students in Grades 6 through 8.

The primary objective of the RLS is to provide students with online experiences designed to increase the level of student engagement as an avenue toward increasing academic achievement. The RLS attempts to accomplish this objective by recognizing that (a) each student is unique, thereby requiring unique learning experiences; (b) learning is more effective when students enjoy what they are doing; (c) learning is more meaningful when it occurs 
within the context of a real-world problem; and (d) students need opportunities to apply learning in areas of personal interest, relevance, and preferences (Renzulli \& Reis, 2005). Furthermore, Renzulli and Reis (2005) have noted that student engagement in curricular activities can positively impact student learning by precipitating curiosity, self-motivation, and requisite organizational and time management skills.

In the RLS system, students are prompted to answer a series of questions regarding their individual interests and preferred methods of learning. Based upon student responses to the aforementioned questions, the RLS develops a personalized profile-Talent Development Profile (TDP) — that summarizes a student's talents, interests, and learning styles. The TDP is a collection of online and print enrichment activities related to student interests that the student completes either individually or collaboratively. These activities can include virtual field trips, creative training activities, activities in critical thinking, and websites based on personal interest (Renzulli Learning System, 2011). In addition to the TDP, the RLS contains a Renzulli Differentiation Search Engine, a Lesson Planning and Differentiation Tool, and a Total Talent Portfolio-all of which are designed collectively to support teachers in effectively implementing the RLS in their classrooms.

RLS is a web-based application designed to increase teacher productivity and student learning by facilitating the differentiation of curriculum. This computer-based program establishes a profile of students' interests, learning styles, and academic strengths, and then directs the students to teacher-selected activities that are aligned with students' ability levels and interests (Renzulli \& Reis, 2005). Furthermore, students and teachers are able to assess the quality of students' products using the RLS rubric.

\section{Purpose of the Study}

A review of current literature regarding online programs designed to support students with special needs underscored a lack of research-based products that yield beneficial results. As such, little is known about the efficacy of online programs, in general, and the RLS, in particular. Therefore, the purpose of the study was to examine the implementation of the RLS into the teaching and learning environment for middle school students who have been identified as having a learning disability. Should RLS turn out to be to be an effective online program, decision makers within the district under study would have evidence in support of replicating the use of the RLS throughout the district. It is important to note that the intent of the school district where the study took place was to replicate a similar study that focused on general education students who used the RLS. The outcome of the initial study supported the hypothesis of a positive impact on the academic progress of students as a whole. This finding was in concert with the examination of other online instructional programs such as BrainPop, an animated educational website, where elementary students demonstrated marked academic improvement. However, particular attention to the students with special needs was not examined-hence the need for the present study. Although there is an abundance of online instructional programs in K-12 education, a substantial need exists for online instructional materials specifically designed to support the varied academic needs of students with learning disabilities (Edyburn, 2003) — thus, the impetus for this study. 


\section{Research Questions}

The following research questions were addressed in this study:

1) What is the difference in the level of reading achievement between students with learning disabilities who had a high utilization rate of exposure to the RLS and students with learning disabilities who had a low utilization rate of exposure to the RLS in the public school district where the study took place?

2) What is the difference in the level of mathematics achievement between students with learning disabilities who had a high utilization rate of exposure to the RLS and students with learning disabilities who had a low utilization rate of exposure to the RLS in the public school district where the study took place?

\section{Theoretical Frameworks}

Two theoretical perspectives were utilized to guide this study. The researchers believed that pertinent information regarding the nature of students' engagement in the learning process could be derived from the self-determination theory (Deci, Eghrari, Patrick, \& Leone, 1994; Gagné \& Deci, 2005). Three factors identified by Deci et al. (1994) in their self-determination studies that influenced students' intrinsic motivation to learn were: (a) incorporating meaning-driven activities relevant to students, (b) acknowledging students' feelings by engaging their emotions in the learning process, and (c) providing students with autonomy to make decisions about the selections of tasks to perform and with choices of products to demonstrate their knowledge. Roschelle et al. (2000) admonished that learning for students is optimized through active engagement, real-world experiences, and collaboration among and between students and their teachers.

However, when students are engaged in online instructional programs, some receive less support and guidance from their teachers than with printed lessons (Thompson, Madhuri, \& Taylor, 2008). Therefore, a second theoretical perspective the researchers used to steer this study of the online program came from Jadallah's (1996) reflective theory. This concept is based on the principles and assumptions of the constructivist learning theory in which meaning is constructed through the reflective analysis of experiences (Meichenbaum, 1993). Jadallah (1996) postulated that teachers: (a) construct their understanding of teaching and learning through the interpretation of experiences, (b) examine and evaluate the importance of curriculum and instructional practices for the benefit of students in and out of the school setting, and (c) engage in dialogue about the planning and instructional practices that promote the development of reflective insight. Thus, teachers still are responsible for guiding and facilitating learning for students through online programs. As such, educators also must ensure the use of appropriate online programs designed to support students with special learning needs.

\section{Research Hypothesis}

The research hypothesis for this study was twofold. First, the researchers hypothesized a difference in the level of reading achievement between students with learning disabilities who 
had a high utilization rate of exposure to the RLS and students with learning disabilities who had a low utilization rate of exposure to the RLS system in the school district where the study took place. Second, the researchers hypothesized a difference in the level of mathematics achievement between students with learning disabilities who had a high utilization rate of exposure to the RLS and students with learning disabilities who had a low utilization rate of exposure to the RLS in the school district where the study took place.

\section{Significance of the Study}

It was hoped that findings from this study would help to determine the efficacy of the RLS in improving the academic needs of students with learning disabilities in the areas of reading and mathematics. Also, it was expected that this information would add to the existing literature concerning the efficacy of online instructional tools for students with special learning needs. Lastly, it was hoped that these research findings would provide exemplars of online instructional tools that promote improved academic growth of each participant, namely, the RLS.

\section{Method}

\section{Participants}

The school district where the study took place is a very large public school system located in a state in the southwest area of the United States. During the 2010 - 2011 school year, 203,294 Pre-Kindergarten through 12th grade students were enrolled in the district under study. According to information retrieved from the Academic Excellence Indicator System (AEIS) available on the state's website, the district's diverse population of student ethnicity breakdown was as follows: 53,272 (26.2\%) African Americans; 125,807 (61.9\%) Hispanics; 15,802 (7.8\%) White; 6,254 (3.1\%) Asians; and 2,159 (1\%) combined American Indian, Pacific Islander, and two or more races. Additionally, $80.6 \%(163,905)$ of the district's student population was reported as economically disadvantaged and $64.0 \%(130,190)$ were at-risk.

During the same 2010-2011 school year, the school district under study employed 11,812 teachers, of which 3,062 (25.9\%) were male and 8,750 (74.1\%) were female. The ethnicity make-up of the district's teaching staff was as follows: 36\% (4,326) African-American; $22.4 \%$ $(2,698)$ Hispanic; $37.3 \%(4,492)$ White 0.1\% (15); and 4.1\% (496) Asian. Moreover, the teaching experience of the teachers in the district was indicated as follows: $6.2 \%$ (733) were classified as beginning teachers; $29.7 \%(3,503)$ had 1 to 5 years of experience; $21.3 \%(2,514)$ had 6 to 10 years of experience; $22.5 \%(2,661)$ had 11 to 20 years of experience; and $20.3 \%$ $(2,400)$ had more than 20 years of experience.

Based on the school district's Assessment of Student Performance in Special Education report for Spring 2011 presented by the district's Research and Accountability Department, the district provided services to 16,402 students with disabilities. However, for this study, the state assessment data for the population of sixth-, seventh-, and eighth-grade (2,750 middle school students) students diagnosed as having a learning disability as established by the state's education agency, and who participated in the RLS, were utilized in the investigation. These data were obtained through the district's Research and Accountability Department and only 
included the standard and accommodated (shortened version of the standard state assessment that does not include field test items) versions of the state assessment test. In addition, the participants were enrolled in the district's Title I schools and had 1 year of experience working with RLS. Of the 2,750 students' data retrieved, the state assessment reading scaled scores were available for 1,212 (44\%) students and the state assessment mathematics scaled scores were available for $1,269(46 \%)$ students.

\section{Instruments}

For the purpose of this study, the state assessment data files were utilized. These data were obtained through the district's Research and Accountability Department and only included the standard and accommodated versions of the state assessment. The state assessment is intended to measure the degree to which a student has learned and is able to use the pre-determined knowledge and skills at each tested grade level (Texas Education Agency [TEA], 2012). The accommodated version of the state assessment is a shortened version of the standard state assessment that does not include the field test questions. Additionally, the state test comprises multiple-choice and short-answer items. The stratified coefficient alpha was used by the state education agency (TEA, 2007a) for estimating score reliability of tests with a mixture of item types. The score validity of the test is content based and tied directly to the statewide curriculum (TEA, 2007b). When the state assessment was designed as the standards-referenced assessment for the state curriculum, various professionals (e.g., educators across the state, test developers, test experts) were brought together and committees were formed to develop subject area tests. These content area tests then were administered by subject area and grade level to students through a field test. Afterwards, the established committees reviewed test items for content, bias, and data from the field testing (TEA, 2007b).

\section{Procedure}

The district in this study began the implementation of RLS by first contracting the Renzulli Professional Development team to deliver training to the district's educators. Two methods were incorporated: a train-the-trainer format and campus-based training sessions. Two representatives from each campus were requested to serve as trainers and support personnel on the campus for RLS. Although the developers had suggested procedures for using the RLS in the classroom, the teachers in the district used the RLS in varying degrees based on their classroom structures. However, the RLS was individualized for students in that they could access the program at any time of day from any computer with Internet service and could work independently or collaboratively with their classmates. When students first accessed the RLS, they were asked a series of questions to assess their interest and learning profile. After that, a list of recommendations on learning styles was populated by the system for students to learn various content areas. Moreover, websites for research projects and other activities also were provided by the developers of RLS. Parental permission was not needed for students to participate in the RLS on campus. However, parents were notified about the program and invited to participate.

In this study, state assessment data for the population of sixth-, seventh-, and eighth-grade students (i.e., 2,750 middle school students) diagnosed as having a learning disability as 
established by the state education agency guidelines and who participated in the RLS were obtained also through the Research and Accountability Department of the school district being studied. The participants for whom state assessment scaled scores were available for reading and mathematics were utilized in the study. These data only included results from the standard and accommodated versions of the state assessment.

\section{Analysis}

A one-way multivariate analysis of variance (MANOVA) was conducted to examine simultaneously high and low utilization of RLS with respect to state assessment reading and mathematics scaled scores. A 5\% level of significance was used. Also, an effect size (i.e., $\eta^{2}$ ) was computed. A discriminant analysis was used as a follow-up to the MANOVA.

\section{Results}

The standardized skewness coefficient and standardized kurtosis coefficient for both reading achievement and mathematics achievement for students diagnosed with specific learning disabilities were calculated by dividing each coefficient by the respective standard error (e.g., standardized skewness for students' reading scores divided by the standard error of skewness $=2.39$ and standardized kurtosis for students' reading scores divided by the standard error of kurtosis $=3.65$ ). The standardized skewness of students' reading scale scores was between -3.00 and 3.00; however, the standardized kurtosis was outside the \pm 3 range, indicating a leptokurtic distribution. Thus, the standardized kurtosis for reading scores of students indicated non-normality (Onwuegbuzie \& Daniel, 2002). Additionally, the standardized skewness coefficient for mathematics scores of students with special learning disabilities (7.17) and the standardized kurtosis coefficient (7.45) were both outside the bounds of normality, indicating a positively skewed distribution and a leptokurtic distribution. Thus, caution should be employed when interpreting the results generated from the MANOVA.

According to Field (2009), MANOVA requires the assumption of multivariate normality. One condition that must be satisfied in gauging multivariate normality is that of determining the univariate normality for each dependent variable. Although univariate normality will not guarantee the multivariate normality, this approach is still useful in speculating normality of variables in MANOVA (Field, 2009). Simply put, if the univariate analysis does not indicate normality between each dependent variable, multivariate normality is not expected. Yet, multivariate normality is not certain even if there is univariate normality. The assumption of multivariate normality is more rigorous because it entails each individual variable to have a normal distribution and that the combined distribution of the variables is multivariate normal (Bray \& Maxwell, 1985). In any case, the fact that the univariate normality assumption was not met suggested that the multivariate normality likely was not met. Thus, as stated previously, the MANOVA findings should be interpreted with caution.

A MANOVA was conducted to examine simultaneously high and low utilization of RLS with respect to the state assessment reading and mathematics scaled scores. Before conducting this analysis, a Box's $M$ test was performed to evaluate the homogeneity of the 
variance-covariance matrix involving the variables of interest, namely, reading scaled scores and mathematics scaled scores of students with learning disabilities (Tabachnick \& Fidell, 2007). Box's $M$ value was 4.52 , which suggested no heterogeneity of the variance-covariance matrix $(F[3,106338.88]=1.49, p=.22)$.

The MANOVA revealed a statistically significant main effect for the group variable $(F[2,1047]=5.20, p=.006$; Wilks' Lambda $=1.00)$. In addition, the effect size, as measured by $\eta^{2}$, related to the utilization of the RLS program difference was 0.01 . According to Cohen's (1988) criteria, this coefficient indicated a very small effect size. Consequently, both the reading and the mathematics scaled scores were influenced by the utilization of RLS. The descriptive statistics related to the mathematics and the reading scores of the study participants are displayed in Table 1.

Table 1: Mean and Standard Deviation for Selected Variables as a Function of Utilization

\begin{tabular}{lcccccc}
\hline & \multicolumn{2}{c}{ High Utilization } & \multicolumn{4}{c}{ Low Utilization } \\
Variables & $n$ & $M$ & $S D$ & $n$ & $M$ & $S D$ \\
\hline $\begin{array}{l}\text { Reading } \\
\text { Scale Score }\end{array}$ & 56 & 663.89 & 79.34 & 994 & 651.40 & 94.62 \\
& & & & & & \\
Mathematics & & & & & & \\
Scale Score & 56 & 629.14 & 74.87 & 994 & 650.45 & 76.49 \\
\hline
\end{tabular}

In view of the fact that the MANOVA resulted in a statistically significant main effect and because numerous statisticians have recommended it as a follow-up analysis to the MANOVA (e.g., Field, 2009; Huberty \& Morris, 1989; Keselman et al., 1998; Onwuegbuzie \& Daniel, 2003), a discriminant analysis was conducted. The discriminant analysis revealed a statistically significant canonical function $\left(\chi^{2}[2]=10.34, p=.006\right.$; Wilks' Lambda $\left.=0.99\right)$. In addition, the canonical correlation was .10 and according to Cohen's (1988) criteria, this coefficient indicated a small effect size. Moreover, the average score on the discriminant function for students in both groups (i.e., group centroid) was 0.02 for low utilization of RLS and -0.42 for high utilization of RLS. These statistics revealed that the discriminant function clearly distinguished between high and low utilization of RLS among students with learning disabilities.

A review of the standardized canonical discriminant function coefficients, using the recommended cutoff correlation of 0.3 by Lambert and Durand (1975) as a suitable minimum coefficient, indicated that both the reading and the mathematics scaled scores were practically significant. Moreover, the structure coefficients (i.e., structure matrix) for mathematics and reading scaled scores using the recommended cutoff correlation of 0.3 (Lambert \& Durand, 1975), pointed to the fact that both variables discriminated (Table 2) students who had high utilization from those who had low utilization of RLS. High scaled scores were indicative of the reading scaled scores, which suggested that students high on this variable were more 
prone to higher utilization of RLS. On the other hand, lower scaled scores were associated with the mathematics scaled scores.

Table 2: Standardized and Structure Coefficients for Designated Variables

Variable

Standardized Coefficient

Structure Coefficient

Reading Scaled Score

$-0.93^{*}$

$-.30^{*}$

Mathematics Scaled Score

$1.14^{*}$

$.63^{*}$

*Coefficients with effect sizes larger than .3 (Lambert \& Durand, 1975)

An assessment of the standardized and structure coefficients exposed no suppressor variables. The mathematics scaled score variable contained a significant standardized coefficient (i.e., > .30) and a significant structure coefficient (Henson, 2002; Onwuegbuzie \& Daniel, 2003). Similarly, the reading scaled score also had significant structure and standardized coefficients, although the standardized coefficient was close to the cutoff point of 0.3 (Lambert \& Durand, 1975). In conclusion, both the reading and the mathematics scaled scores contributed to discriminating high and low utilization of RLS among students with learning disabilities, with the mathematics scaled score making the greatest impact.

\section{Discussion}

An important question we pondered throughout our research was, "What is the educational significance of this study?" That is to say, how will our study impact the academic progress of students with disabilities so that viable solutions can be developed for further academic progress? As indicated previously, educational leaders continue to struggle with the implementation of effective online instructional tools as a means of supporting the needs of students with special needs (Papa, 2010). Based on our research, those students whose teachers did not follow the implementation strategies provided by the RLS did not succeed at high levels on the mathematics assessment. Further research could focus on the difference in the success of students on the reading assessment in contrast with the students' lack of success on the mathematics assessment.

A review of the data related to the present study revealed a positive impact on the reading scores and a negative impact on the mathematics scores when participants experienced high utilization of the RLS. The researchers surmised that the inconsistency between the results of reading and mathematics scores of participants who experienced high utilization of the RLS might relate to how teachers implemented the RLS in the learning environment. Based upon our findings and the review of the literature, it appears that reading teachers might have had increased involvement in the learning process with their students as students engaged in online instructional activities. Taking the reflective theory into account, Jadallah (1996) postulated that teachers are responsible for examining and evaluating the importance of curriculum and instructional practices for the benefit of students 
in and out of the school setting. Moreover, other researchers contend that implementation of an effective online instructional program must embrace high expectations, cooperation, and learner-centered activities that promote opportunities for ample practice and feedback (Brown, 2004; Chickering \& Ehrmann, 1996; Jonasen et al., 2005; Lim \& Kim, 2003).

The information presented in this study has several implications for further research related to meaning-driven activities, instructional practice, and engagement. As it relates to meaning-driven activities, research investigations might be conducted to compare the perceptions of students and teachers related to what constitutes a meaning-driven activity in online instructional programs. With reference to the second implication, instructional practice, possible research might focus on the differences in the instructional practices employed among the reading and the mathematics teachers who used RLS as a part of the teaching and learning process. Finally, based upon Thompson et al.'s (2008) findings that students receive less support and guidance from their teachers during online instruction than with printed lessons, another research endeavor might investigate what contributing factors influence the engagement of both students and teachers as partners in the learning process as students are introduced and engaged in online instructional programs. Moreover, our review of the research regarding the use of online instructional programs revealed a positive impact on student achievement with regard to students in a general education setting. However, additional research is warranted to evaluate the different types of instructional settings available in schools that might influence the effective implementation of online instructional programs.

As with any research endeavor, threats to the internal validity and external validity of the findings prevailed. Therefore, the internal validity and external validity threats presented within this study were considered and addressed accordingly. The internal validity threats associated with the findings of this particular study included maturation and history. Maturation refers to the biological and psychological changes or conditions that naturally occur with the passage of time (Russ-Eft \& Hoover, 2005). Considering the fact that the population under study represented students with special learning needs, the expected biological and psychological changes might or might not have occurred at the same rate as those for students who did not possess special learning needs. Therefore, consideration for a regression or lack of maturation within the participant group should be expected and taken into account when interpreting the results of the study. As such, the growth-or lack thereof-experienced among the students could be attributed to the natural changes that took place within the participants. Students with special learning needs will have varying levels of disability (e.g., learning disabled, mental retardation) that will range from one extreme level of physiological and biological growth to another. Therefore, the threat of maturation was controlled by limiting the participant inclusion in this study to students who have been identified as having a specific learning disability, thereby ensuring that the aforementioned changes are manifested equally among the participants.

The second internal validity threat to the findings of this study refers to the presence of extraneous variables (Onwuegbuzie, 2003). Extraneous variables related to this study include the various instructional methods employed by the teachers of study participants, prior 
computer experience of the participants, and personal preferences of the participants using the RLS system. Given the fact that the study did not require every teacher to use the same instructional methods for all participants, specific measures taken within an individual classroom might have accounted for study outcomes and have had no relationship with the use of the RLS. Likewise, a participant with more familiarity with technology than did another participant might have accounted for study outcomes and have had no relation to the use of the RLS. Therefore, Cook and Campbell (1979) recommended randomly testing both the control and experimental groups as a measure toward minimizing the threat of history. Because this study only contained one group of participants who experienced two levels of utilization (i.e., low utilization and high utilization), the participants utilized the RLS at randomized junctures (e.g., during school hours, after school hours, weekdays, and weekends). Furthermore, it is important to note that the absence of a pretest in this study prohibits a definitive assessment of additional internal threats to validity such as maturation and statistical regression.

In addition to the internal threats to validity, the researchers of this study considered the varying external threats to validity while minimizing any related effects. External threats to this study included novelty effects and multiple treatment interference (Cook \& Campbell, 1979). Thusly, the presence of novelty effects was determined as a possible threat to the outcomes experienced within this study. Given the introduction of a highly interactive technological product to engage learners, an increased level of interest among student participants was inevitable because it provided a new and exciting learning environment that engaged a variety of senses. In addition, the use of the RLS was not the only program implemented to increase student achievement among students with learning disabilities (e.g., targeted instruction and pull-out programs for select groups of students, newly implemented instructional strategies, and the presence of additional personnel in classrooms). Therefore, a definitively causal relationship between the use of the RLS and student achievement amongst students with special learning needs - without consideration for each of the various measures employed - cannot be determined. Moreover, a generalization of study findings to all students with special learning needs cannot be made without adhering to Onwuegbuzie's (2003) recommendation of replicating the study in a variety of settings, a method deemed most effective toward assessing the external validity of findings.

Renzulli notes the need to supplement the regular curriculum with the Renzulli system; the main goal of the RLS is to provide students with experiences that help them enjoy the process of learning through their personal engagement. Engagement is achieved by providing students with highly challenging but personally meaningful activities that take into account their academic strengths, interests, and learning style preferences. When students are engaged in learning, they are motivated to pursue greater challenges and to develop a sense of self-satisfaction and accomplishment. Highly motivated students are involved in activities beyond what is required academically. The goal of RLS is to create a high level of engagement in the academic curriculum, which is a better predictor of school success than are test scores. With the increasing pressure on teachers to strengthen the reading scores of students on standardized tests, RLS can provide support in increasing the assessment scores of students who have a specific learning disability in reading, but might not turn out to be as beneficial 
when utilized in the area of mathematics. As such, students who have been identified as students with a specific learning disability might find another resource more beneficial toward improving mathematics scores than the RLS. It is imperative to account for the fact that regardless of the online, face-to-face, or any other avenue of instructional delivery, positive learning experiences are the desired outcome for all students, in general, and students with special needs, in particular.

\section{References}

Anderson, R., \& Balajthy, E. (2009). Stories about struggling readers and technology. The Reading Teacher, 62, 540-542. http://dx.doi.org/10.1598/RT.62.6.9

Ash, K. (2011, August 2). K-12 technology, data firms thrive, study says. Education Week. Retrieved from http://gsehd.gwu.edu/documents/gsehd/resources/gwuohs-onlineresources/assessmentdat a/educationweek_k12techdatafirmsthrive-08022011.pdf.

Babbitt, B., \& Miller, S. (1996). Using hypermedia to improve the mathematics problem-solving skills of students with disabilities. Journal of Learning Disabilities, 29, 391-401. http://dx.doi.org/10.1177/002221949602900407

Bonner, J. L. (2011, February 27). Idaho's education reforms attract computer makers. Real Clear Politics. Retrieved from http://www.realclearpolitics.com/printpage/?url=http://www.realclearpolitics.com/news/ ap/politics/2011/Feb/27/idaho_s_education_reforms_attract_computer_makers.html.

Bray, J. H., \& Maxwell, S. E. (1985). Multivariate analysis of variance. Beverly Hills, CA: Sage.

Brown, K. (2004). September/October). Technology: Building interaction. TechTrends, $48(5)$.

Chickering, A. W., \& Ehrmann, S. C. (1996, October, 3-6). Implementing the seven principles: Technology as lever. AAHE Bulletin.

Cohen, J. (1988). Statistical power analysis for the behavioral sciences (2nd ed.). Hillsdale, NJ: Lawrence Erlbaum.

Condie, R., \& Livingston, K. (2007). Blending online learning with traditional approaches: Changing practices. British Journal of Educational Technology, 38, 337 - 348. http://dx.doi.org/10.1111/j.1467-8535.1006.006.30.x

Cook, T. D., \& Campbell, D. T. (1979). Quasi-experimentation: Design and analysis issues for field settings. Boston, MA: Houghton Mifflin Company.

Deci, E. L., Eghrari, H., Patrick, B. C., \& Leone, D. R. (1994). Facilitating internalization: The self-determination theory perspective. Journal of Personality, 62, 119-142. http://dx.doi.org/10.1111/j.1467-6494.1994.tb00797.x 
Doering, A. (2005, March). Adventure learning. Paper presented at the meeting of the Society for Information Technology and Teacher Education Conference, Phoenix, AZ.

Edyburn, D. (2003). Measuring assistive technology outcomes in writing. Journal of Special Education Technology, 18(2), 60-64.

Engel, E. (2011, September, 28). iPads enter the classroom. Journal Star. Retrieved from http://www.pjstar.com/business/x609832039/iPads-enter-the-classroom.

Field, A. (2009). Discovering statistics using SPSS (3rd ed.). London, England: Sage.

Gagné, M., \& Deci, E. (2005). Self-determination theory and work motivation. Journal of Organizational Behavior, 26, 331-362.

Henson, R. K. (2002, April). The logic and interpretation of structure coefficients in multivariate general linear model analyses. Paper presented at the annual meeting of the American Educational Research Association, New Orleans, LA.

Herrington, J., \& Oliver, R. (1999). Using situated learning and multimedia to investigate higher-order thinking. Journal of Interactive Learning Research, 10(1), 3-24.

Huberty, C. J., \& Morris, J. D. (1989). Multivariate analysis versus multiple univariate analyses. Psychological Bulletin, 302-308. doi:10.1037//0033-2909.105.2.302

Jadallah, E. (1996). Reflective theory and practice: A constructivist process for curriculum and instructional decisions. Action in Teacher Education, 18, 73-85. http://dx.doi.org/10.1080/01626620.1996.10462835

Jonasen, D. H., Strobel, J., \& Gottdenker, J. G. (2005). Modeling for meaningful learning. In Learning Sciences and Technologies Group (Ed.), Engaged learning with emerging technologies (pp. 1-28). Drodrecht, NL: Springer Verlag.

Keselman, H. J., Huberty, C. J., Lix, L. M., Olejnik, S., Cribbie, R. A., Donahue, B., Kowalchuk, R. K., Lowman, L. L., Petoskey, M. D., Keselman, J. C., \& Levin, J. R. (1998). Statistical practices of educational researchers: An analysis of their ANOVA, MANOVA, and ANCOVA analyses. Review of Educational Research, 68, 350-386. http://dx.doi.org/10.2307/1170601

King, M. (2011, November 17). Amazon donation puts Kindles in every classroom at Midlands school. Retrieved from http://www.wistv.com/story/16068944/christmas-comes-early-for-some-students

Koszalka, T. A., \& Ganesan, R. (2004). Designing online courses: A taxonomy to guide strategic use of features in course management systems (CMS) in distance education. Distance Education, 25, 243-256. http://dx.doi.org/10.1080/0158791042000262111

Lambert, Z., \& Durand, D. (1975). Some precautions in using canonical analysis. Journal of Market Research, XII, 468-475. http://doi:10.2307/3151100 


\section{I Macrothink}

International Journal of Education ISSN 1948-5476 2012, Vol. 4, No. 3

Lim, D., \& Kim, H. (2003). Motivation and learner characteristics affecting online learning and learning application. Journal of Educational Technology Systems, 31, 423-439. http://dx.doi.org/10.2190/OLWO-KE8X-MDYH-X27F

Martindale, T., Cates, W., \& Qian, Y. (2003). Educational Web sites: A classification system for educators and learners. Educational Technology, 43(6), 47-50.

Martindale, T., Pearson, C., Curda, L. K., \& Pilcher, J. (2005). Effects of an online instructional application on reading and mathematics standardized tests scores. Journal of Research on Technology in Education, 37, 349-360.

Meichenbaum, D. (1993). Changing conceptions of cognitive behavior modifications: Retrospect and prospect. Journal of Consulting and Clinical Psychology, 61, 202-204. http://dx.doi.org/10.1037//0022-006X.61.2.202

Meyen, E. L., Aust, R., Gauch, J. M., Hinton, H. S., Isaacson, R. E..Smith, S. J., \& Tee, M. Y. (2002). e-Learning: A programmatic research construct for the future. Journal of Special Education Technology, 17(3), 37-46.

Mezirow, J. (1991). Transformative dimension of adult learning. San Francisco, CA: Jossey-Bass.

Nicaise, M. (1997). Computer-supported apprenticeships in math and science. Journal of Computers in Mathematics and Science Teaching, 16, 443-465.

Onwuegbuzie, A. J. (2003). Expanding the framework of internal and external validity in quantitative research. Research in the Schools, 10(1), 71-90.

Onwuegbuzie, A. J., \& Daniel, L. G. (2002). Uses and misuses of the correlation coefficient. Research in the Schools, 9(1), 73-90.

Onwuegbuzie, A. J., \& Daniel, L. G. (2003, February 12). Typology of analytical and interpretational errors in quantitative and qualitative educational research. Current Issues in Education, 6(2). Retrieved from http://cie.ed.asu.edu/volume6/number2/

Palloff, R., \& Pratt, K. (1999). Building learning communities in cyberspace. San Francisco, CA: Jossey-Bass.

Paolucci, R. (1998). The effects of cognitive style and knowledge structure on performance using a hypermedia learning system. Journal of Educational Multimedia and Hypermedia, $7(2 / 3), 123-150$.

Papa, R. P. (2010). Technology leadership for school improvement. Thousand Oaks, CA: Sage.

Renzulli Learning System. (2011). Renzulli Learning Tools and Services. Retrieved from http://www.renzullilearningsystems.com/toolsandservices.aspx

Renzulli, J. S. \& Reis, S. M. (2005). A technology based program that matches enrichment resources with student strengths. iJET International Journal of Emerging Technologies in Learning, 1-12. Retrieved from http://online-journals.org/i-jet/article/view/126/0 
Roschelle, J. M., Pea, R. D., Hoadley, C. M., Gordin, D. N., \& Means, B. M. (2000). Changing how and what children learn in school with computer-based technologies. The Future of Children: Children and Computer Technology, 10, 76-101. http://dx.doi.org/10.2307/1602690

Russ-Eft, D., \& Hoover, A. L. (2005). Experimental and quasi-experimental designs. In R. A. Swanson and E. F. Holton (eds.), Research in organizations: Foundations and methods of inquiry (pp. 75-95). San Francisco, CA: Berrett-Koehler.

Simonson, M., Smaldino, S., Albright, M., \& Zvacek, S. (2003). Teaching and learning at a distance. Upper Saddle River, NJ: Erlbaum Associates.

Snider, R. C. (1992). The machine in the classroom. Phi Delta Kappan, 74, 316-323.

Tabachnick, B. G., \& Fidell, L. S. (2007). Using multivariate statistics (5th ed.). Boston, MA: Allyn \& Bacon.

Texas Education Agency. (2007a). Chapter 16: Reliability. Technical Digest 2006 - 2007, 167-176.

Retrieved

from

http://www.tea.state.tx.us/WorkArea/DownloadAsset.aspx?id=2147493999

Texas Education Agency. (2007b). Chapter 17: Validity. Technical Digest 2006 - 2007, 177-184. Retrieved from http://www.tea.state.tx.us/WorkArea/DownloadAsset.aspx?id=2147494000

Texas Education Agency. (2012). TAKS Resources. Retrieved from http://www.tea.state.tx.us/student.assessment/taks

The Sloan Consortium. (2008). Staying the course: Online education in the United States. Retrieved from http://www.sloanc.org/publications/survey/pdf/staying_the_course.pdf

Thompson, G., Madhuri, M., \& Taylor, D. (2008). How the Accelerated Reader program can become counterproductive for high school students. Journal of Adolescent \& Adult Literacy, 51, 550-560. http://dx.doi.org/10.1598/JAAL.51.7.3

Watson. J., \& Ryan, J. (2007). Keeping pace with online learning: A review of state level policy and practice. Evergreen, CO: Evergreen Consulting Associates.

\section{Copyright Disclaimer}

Copyright reserved by the author(s).

This article is an open-access article distributed under the terms and conditions of the Creative Commons Attribution license (http://creativecommons.org/licenses/by/3.0/). 